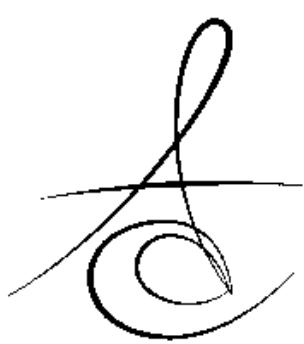

\section{SUBMANDİBULAR DEV SİALOLİTİN ENDOSKOPİ YARDIMI İLE DİAGNOZU VE} TEDAVISII: OLGU SUNUMU

\section{ENDOSCOPIC ASSISTED DIAGNOSIS AND MANAGEMENT OF GIANT SUBMANDIBULAR SIALOLITH: A CASE PRESENTATION}

\author{
Dr. Dt. Cem ÜNGÖR* \\ Dt. Fatih TAŞKESEN*
}

Makale Kodu/Article code: 1256

Makale Gönderilme tarihi: 13.08.2013

Kabul Tarihi: 31.10.2013

\section{ÖZET}

Sialolithiazis teşhisi ve tedavisi hala tartışılır olan major tükürük bezlerinin genel bir patolojisidir. Tükürük bezlerinin ve tükrük bezi kanallarının endoskopisi, tükürük bezi hastalıkların tam olarak teşhisini ve minimal invazif cerrahi tedavisini sağlamaktadır. Endoskopik aletlerde çoğunlukla minyatürize olmaları şeklindeki gelişmeler, endoskopinin tükrük bezi cerrahisinde kullanımını artırmıştır. Bu vaka raporunun amacı, endoskopi kullanımının submandibular sialolithiazisin teşhisinde ve tedavisinde uygun bir teknik olduğunu sunmaktır.

Anahtar Sözcükler: Submandibular tükürük bezi, sialolithiazis, sialolit, endoskopi

\section{GİRİş}

Obstrüktif tükürük bezi rahatsızlığı, tükürük bezlerini etkileyen en önemli problemdir ve tükürük bezi disfonksiyonu ile sialoadenektominin en önemli nedenidir. Sialolithiazis, "sialolit" olarak tanımlanan tükürük bezi taşlarının gelişimi ile oluşan bir rahatsızııtır. ${ }^{1}$ Sialolitler, tükürük bezi kanalında biriken debrislerin (bakteri, mukus, deskuame hücreler v.b.) mineralizasyonu neticesinde oluşur ve \% 82 inorganik ve $\% 18$ organik yapıdadırlar. Kimyasal olarak, birçok sialolit, hidroksiapatit formundaki kalsiyum fosfat ve az miktarda magnezyum, potasyum, sodyum, demir, silikon ve klorid içermektedir. Bazik kalsiyum fosfat tuzlarına bağlı olarak tükürük sekresyonu aşırı doygunluğa ulaşıp çökelerek sialolit formasyonuna neden olabilir. ${ }^{2}$

\section{ABSTRACT}

Sialolithiasis is a common pathology of the major salivary glands, yet its accurate detection and treatment is still intriguing. The endoscopy of the salivary glands and ducts of these glands provides an accurate diagnosis and aids minimally invasive surgical treatment for salivary gland diseases. The use of endoscopy in salivary gland surgery have increased due to advancements in endoscopic equipments particularly miniaturization. The aim of this case report is to present the use of endoscopy as a technique for diagnosing and management of submandibular sialolithiasis.

Key words: Submandibular salivary gland, sialolithiasis, sialolith, endoscopy

Tükürük bezi taşları \% 80 oranında submandibular bezde ya da ona ait kanalda görülmektedir. Bu bezde sialolit oluşumu, tükürük akışının yerçekimine karşı olması ve daha yavaş olması, yüksek musin ve tuz içeriği gibi sebepler nedeniyle diğer tükürük bezlerine göre daha yüksektir. ${ }^{3}$ Erişkin popülasyonda görülme sıklığı \% 0.12' dir ve erkeklerde kadınlara oranla iki kat daha fazla gözükür. ${ }^{4}$ Sıklıkla yemek yeme esnasında ilgili bezde şişlik ve ağrı ile karakterizedir. Sialolitin tükürük bezi kanalını tıkamasına bağlı biriken tükrüğün enfekte olması mümkündür. ${ }^{1}$

Sialolitler genelde 3-7 mm büyüklüğündedirler nadir olarak da $15 \mathrm{~mm}$ kadar büyüyebilirler. 15 mm' den büyük tükürük bezi taşları megalitler olarak sınıflandırılırlar ve tedavileri değişik yöntemleri içermektedir. ${ }^{5}$ Tükürük bezi taşlarının teşhisi için ultrasonografi ilk seçenek olarak görülmektedir.

${ }^{*}$ Karadeniz Technical University Faculty of Dentistry Department of Oral and Maxillofacial Surgery 
Atatürk Üniv. Diş Hek. Fak. Derg.

J Dent Fac Atatürk Uni

Cilt:24, Sayı:1, Yıl: 2014, Sayfa: 98-101

Sialoendoskopi, sialolitlerin tanısında ve tedavisinde kullanılan güncel bir yöntemdir. Bu minimal invazif yöntem, sialolitin yerinin tam olarak belirlenerek taşın çıkarılmasına ve kanal dilatasyonunun sağlanmasına yardımcı olmaktadır. ${ }^{6}$

Bu makalede, 74 yaşında erkek hastada yapılan rutin kontroller esnasında tespit edilen dev tükürük bezi taşının endoskopi yardımı ile yapılan cerrahi girişimi ve 1 yıllık takibi sunulmaktadır.

\section{VAKA RAPORU}

74 yaşında erkek hasta, Karadeniz Teknik Üniversitesi, Diş Hekimliği Fakültesine protetik rehabilitasyon amacı ile başvurmuştur. Hastanın sistemik problemi bulunmamaktadır. Yapılan klinik muayanede tam dişsiz olan hastanın sağ alt ağız tabanı bölgesinde, palpasyonda belirgin ve ağrısız sert kitle tespit edilmiştir (Resim 1). İlgili bölgede pü akışı izlenmeyip tükrük salgısında azalma olduğu tespit edilmiştir. Radyografik inceleme panaromik grafi ile yapılmıştır. Radyografide, $1,5 \times 3 \mathrm{~cm}$ büyüklüğünde, alveolar krete paralel seyreden radyopak kitle belirlenmiştir (Resim 2).

İşlem lokal anestezi altında gerçekleştirilmiştir. Lingual sinir anestezisi yapıldıktan sonra wharton kanalı hizasınca infiltrasyon anestezi (Artikain hidroklorür) uygulanmıştır. Sialolitin geriye doğru gitmesini engellemek için kanal taşın hemen arkasından 1-0 ipek sütur ile bağlanmıştır. Wharton kanalı ağzı belirlendikten alveolar krete paralel $1 \mathrm{~cm}^{\prime}$ lik kesi yapıldıktan sonra $1,9 \mathrm{~mm}$ dış çapa sahip endoskop (Karl Storz AG, Tuttlingen, Almanya) kanal içerisine yerleştirilmiştir. Taşın büyüklüğü nedeniyle genişleyen submandibular tükrük bezi kanal, endoskobun rahat manevra yapabilmesine olanak sağlamıştır. Sialolit ve kanal duvarları teşhis edildikten sonra, endoskopik disektör yardımı ile sialolit kanal duvarından serbestleştirilmiştir (Resim 3). Anteriora doğru konumlandırılan tükrük bezi taşı, endoskobik forseps ile tek parça halinde çıkarımıştır. 1,8×2,1×3,6 büyüklüğündeki sialolit histopatolojik incelemeye gönderilmiştir (Resim 4). Wharton kanalı serum fizyolojik ile irrige edildikten sonra kanal ağzında oluşturulan kesi 4-0 vicril sutur ile suture edilmiştir. Yapılan histopatolojik inceleme sonucunda submandibular tükrük bezi taşı tanısı doğrulanmıştır. Hastaya post operatif dönemde antibiyotik
ÜNGÖR, COŞKUN,

TAŞKESEN, CEZAİRLİ

(Augmentin, $1000 \mathrm{mg}$, oral tablet), analjezik (Apranax Fort, $550 \mathrm{mg}$, oral tablet) ve gargara (Kloroben, oral gargara) reçete edilmiştir.

Hastanın yapılan 1 yıllık kontrollerinde komplikasyona rastlanmamıştır ve tükrük bezi kanalından normal tükrük akışı izlenmiştir (Resim 5).

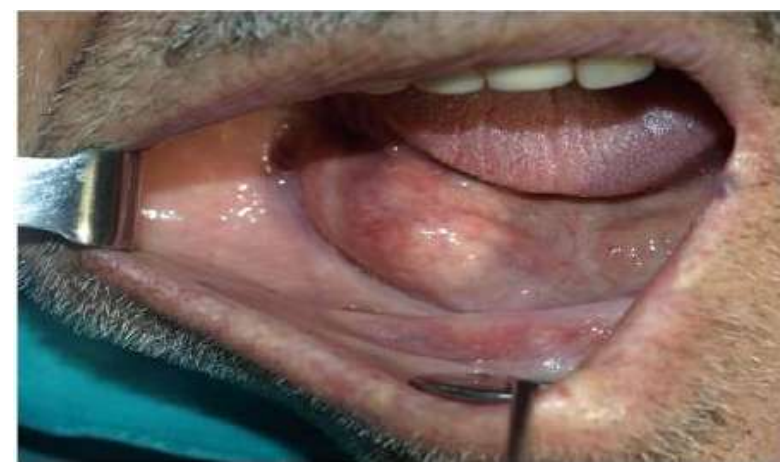

Resim 1. Hastanın preoperatif intraoral görünümü

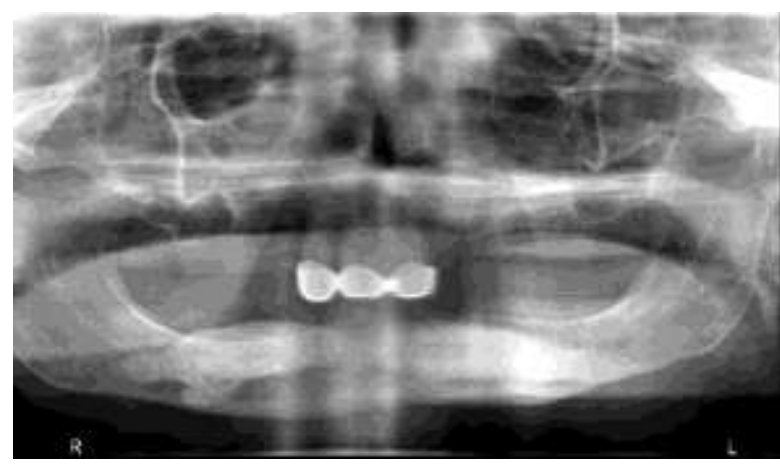

Resim 2. Hastanın panaromik radyografisinin görünümü

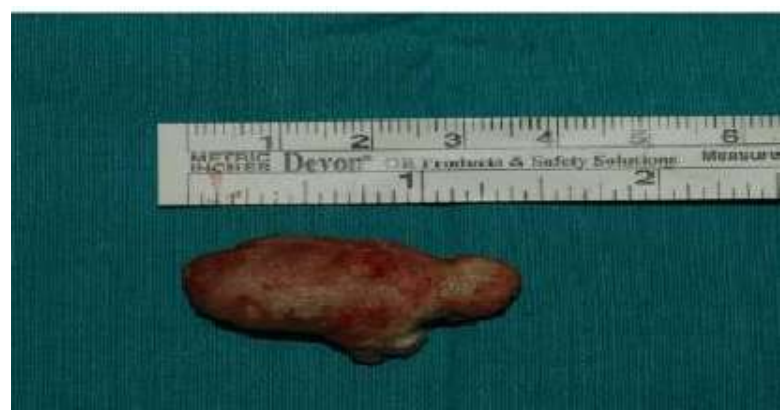

Resim 3. Sialolitin görünümü 
Atatürk Üniv. Diş Hek. Fak. Derg.

J Dent Fac Atatürk Uni

Cilt:24, Sayı:1, Yıl: 2014, Sayfa: 98-101

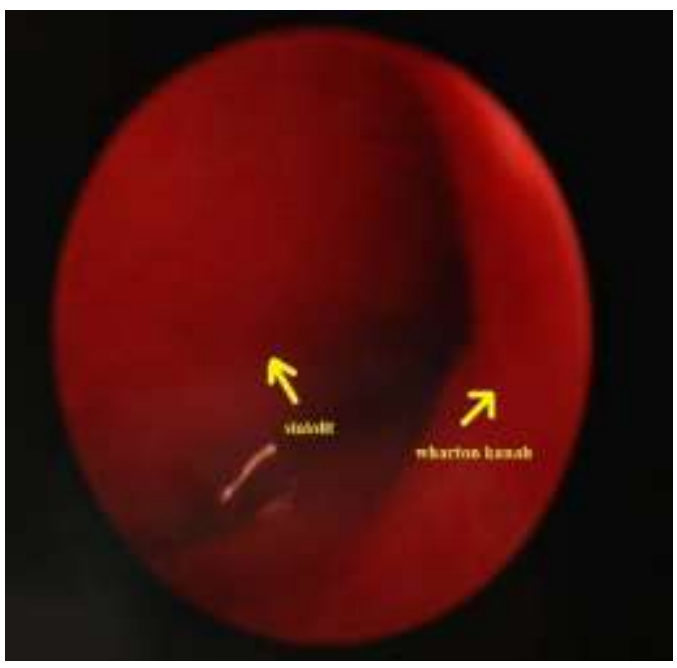

Resim 4. Sialolitin endoskopik görünümü

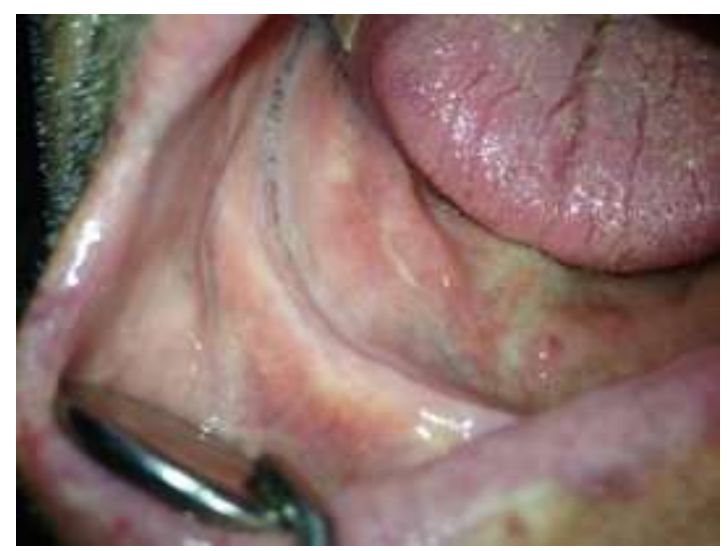

Resim 5. Hastanın postoperatif intraoral görünümü

\section{TARTIŞMA}

Sialoendoskopi ilk olarak 1991 yılında Katz tarafından tanıtılmıştır. ${ }^{7}$ Optik teknolojideki büyük gelişmeler ve endoskopik sistemlerin giderek minyatürize edilmesi duktal sistemin daha kapsamlı bir şekilde taranmasına, obstrüksiyonların tam olarak belirlenmesine ve uygun tedavi metodunun seçilmesine olanak sağlamaktadır. $^{8}$

Geleneksel olarak tükrük bezi taşları konvansiyonel radyografiler, ultrasonografi, sintigrafi, manyetik rezonans, bilgisayarlı tomografi ve sialografi ile tespit edilirler. Endoskopik yaklaşımlar sialolitin hem diagnozuna hem de tedavisine olanak sağlamaktadır. ${ }^{2}$
ÜNGÖR, COŞKUN,

TAŞKESEN, CEZAÍRLI
Nahlieli ve ark. ${ }^{9}$ duktal yapının tam anlamıyla belirlenmesi, tükrük bezi kanalı ağzında oluşabilecek ödemin engellemesi ve sialolitten kopan parçaların yıkanarak uzaklaştırımasına olanak vermesi sebebiyle sialolit cerrahisinde endoskopik yöntemleri önermektedir. Ayrıca endoskopik girişimler sonrasında oral ve duktal mukozanın iyileşmesinin daha güçlü olduğu tespit edilmiştir.

Sialoendoskopi yöntemi, özellikle semi-rijit sistemler kullanıldığı takdirde bazı komplikasyonların oluşmasına neden olabilir. Özellikle kanal içerisinden çalışılan girişimsel tekniklerde kuramsal olarak perforasyon ile damar veya sinir hasarı görülebilir. ${ }^{10,11}$ Sunduğumuz olguda, sialolitin büyüklüğüne bağlı olarak duktal yolun genişlemesi endoskopi aygıtının rahatıkla hareket etmesine izin vermiştir. Hastada peri ve postoperatif dönemde komplikasyon gelişmemiştir.

Endoskopi ile kombine litotripsi uygulamaları günümüzde yaygınlık kazanmıştır. Bu uygulamanın temelini, işlem esnasında oluşturulan kavitasyon etkisi oluşturmaktadır. Bu sayede sialolit duktal kanal duvarından serbestleştirilerek direkt iletilen dalgalar sayesinde parçalanarak uzaklaştırılır. Bu yöntem özellikle sialolitin tükrük bezine yakın olduğu durumlarda ve sayısının birden fazla olduğu olgularda önerilmektedir. ${ }^{2}$

Sialolitlerin tedavisinde cerrahi girişimler ön plandadır. İntraoral yaklaşım, sialoendoskopi ve ilgili bezin eksizyonu bu girişimlerin temelini oluşturmaktadır. Tedavi planı belirlenirken, semptomların süresine ve sayısına, sialolitin büyüklüğüne ve lokalizasyonuna dikkat edilir. Submandibular sialolithiazis mandibular 1. moların transvers yöndeki ilişkisine göre sınıflandırılır. Bu hattın önünde kalanlar anterior, arkasında kalanlar posterior olarak sınıflandırılır. Anteriora lokalize olgularda intraoral yaklaşım önerilirken, posterior konumlu vakalarda ekstraoral yaklaşım ve sialoadenektomi önerilmektedir. ${ }^{6}$ Sunulan olguda, sialolitin anterior konumda olması rağmen büyüklüğü intraoral yaklaşım açısından komplikasyon riskini artırmaktadır. Bu sebeple intraoral girişim ile kombine endoskopik yöntem tercih edilmiş olup, morbidite riski en aza indirilmiştir.

Sialolithiazis olgularında kullanılan endoskopik sistemler, çok yararlı ve uygulanabilir minimal invazif yöntemdir. Bu sistemler sayesinde işlem esnasında ve sonrasında oluşabilecek komplikasyonlar azaltılmış olup hastanın operasyonu daha rahat tolere etmesi sağlanır.

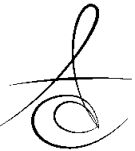




\section{KAYNAKLAR}

1. Su YX, Zhang $K$, Ke ZF, Zheng GS, Chu M, Liao GQ. Increased calcium and decreased magnesium and citrate concentrations of submandibular/ sublingual saliva in sialolithiasis. Arch Oral Biol 2010;55: 15-20.

2. Capaccio P, Torretta S, Ottaviani F, Sambarato G, Pignataro L. Modern management of obstructive salivary diseases. Acta Otorhinolaryngo Ita 2007;27: 161-72.

3. Ayaz ÜY, Dilli A, Hekimoğlu B. Büyük boyutlarda, değişik bir submandibular siyalolityazis olgusu: Direkt radyografi ve ultrasonografi bulguları. Ankara Univ Tıp Fak Mec 2009;62: 69-72.

4. Bayındır T, Çetinkaya Z, Toplu Y, Akarçay M. Ağız içine spontan açılan büyük submandibular sialolitiazis: Olgu sunumu. İnönü Univ Tıp Fak Derg 2012;19: 188-91.

5. Walvekar RR, Tyler PD, Tammareddi N, Peters G. Robotic-assisted transoral removal of a submandibular megalith. Laryngoscope 2011;121: 534-7.

6. Yaman $F$, Gülten Ü, Atılgan $S$. Ağız içine sürmüş submandibular sialolitiazis: Olgu sunumu. Atatürk Univ Diş Hek Fak Derg 2006;16: 70-3.

7. Katz P. Nouvelle therapeutique des lithiases salivares. Inf Dent 1991;73: 3975-9.

8. Chu TW, Chow TL, Lim BH, Kwok SPY. Endoscopic management of submandibular sialolithiasis. Surg Endosc 2003;17: 867-9.

9. Nahlieli O, Baruchin AM. Long-term experience with endoscopic diagnosis and treatment of salivary gland inflammatory diseases. Laryngoscope 2000;110: 988-93.

10. Nahlieli O, Sbacbam B, Zaguri A. Combined external lithotripsy and endoscopic techniques for advanced sialolithiasis cases. J Oral Maxillofac Surg 2010;68: 347-53.

11. Şerbetçi E, Şengör GA. Sialoendoskopi (Tükürük bezi endoskopisi). KBB-Forum 2005;4: 195-7.

\author{
Yazışma Adresi \\ Dr. Cem ÜNGÖR \\ Karadeniz Technical University \\ Faculty of Dentistry \\ Department of Oral and Maxillofacial Surgery, \\ Trabzon, TURKEY \\ Tel 00905322403191 \\ Fax 00904623253017 \\ e-mail cem_ungor@yahoo.com
}

